\title{
COGNITIVE ADVERSE EFFECTS OF LACOSAMIDE IN PATIENTS WITH LOCALIZATION RELATED EPILEPSY - A PROSPECTIVE OBSERVATIONAL STUDY
}

\section{Author information}

1. Dr Sophia B Modi , MD Pharmacology, Government Medical college, Thiruvananthapuram, Kerala, India

2. Dr Asha S, MD Pharmacology, Government Medical college, Thiruvananthapuram, Kerala, India

3. Dr Thomas lype MD, MRCP(UK), FRCP(Edin), DM,Government Medical college,

Thiruvananthapuram , Kerala, India

4. Dr Libu G K, MD Community Medicine, Government Medical college, Thiruvananthapuram, Kerala, India

5. Mrs Reeja Rajan, Neuropsychologist, Government Medical college, Thiruvananthapuram, Kerala, India

\section{Corresponding Author:}

Dr Sophia B Modi

Assistant Professor, Department of Pharmacology, Government Medical college,

Thiruvananthapuram, Kerala, India

Phone number: 9645607555, E-mail address: sophiamodi@yahoo.com 


\section{Declarations}

Funding: Nil

\section{Conflicts of interest/Competing interests : Nil}

Availability of data and material : 'Not applicable'

Code availability : 'Not applicable'

\section{Authors' contributions:}

Study conception, design and material preparation: Dr Sophia B Modi, Dr Thomas lype and Dr Asha S

Data collection : Dr Sophia B Modi, Dr Thomas lype and Mrs Reeja Rajan.

Formal data analysis: Dr Libu GK

Writing - original draft: Dr Sophia B Modi

Writing - review \& editing: Dr Asha S, Dr Sophia B Modi, Dr Thomas lype

All authors read and approved the final manuscript.

Author Affiliation: Government Medical college, Thiruvananthapuram, Kerala, India

Ethics approval : Ethics committee clearance was obtained, informed consent was obtained from each subject / guardian/ relative and confidentiality and anonymity of the patient's information were maintained.

Consent to participate : Informed consent was obtained from each subject / guardian/ relative

Consent for publication : Informed consent was obtained from each subject / guardian/ relative 
medRxiv preprint doi: https://doi.org/10.1101/2021.05.13.21257196; this version posted May 23, 2021. The copyright holder for this preprint

(which was not certified by peer review) is the author/funder, who has granted medRxiv a license to display the preprint in perpetuity.

All rights reserved. No reuse allowed without permission.

\section{COGNITIVE ADVERSE EFFECTS OF LACOSAMIDE IN PATIENTS WITH LOCALIZATION RELATED EPILEPSY} - A PROSPECTIVE OBSERVATIONAL STUDY

Abstract

Newer antiepileptic drugs (AEDs) offer favourable safety profiles than the previously used AEDs. Despite the introduction of many AEDs, a large number of patients continue to suffer from uncontrolled partial-onset seizures which have considerable impact on a patient's quality of life. Lacosamide (LCM) is a third generation AED approved for adjunctive use in partial-onset seizures. Patients with epilepsy frequently experience cognitive dysfunctions due to a variety of factors. Because AEDs are the major therapeutic modality for epilepsy, the adverse effects of AEDs on cognition are important. Objectives: To assess the adverse effects of lacosamide on cognition among patients with localization related epilepsy to whom lacosamide is given as adjuvant therapy. METHODOLOGY : An open labelled prospective observational study in 22 patients who suffered from localization related epilepsy. Results: Average Initial seizure frequency per month was 3.56 (SD 2.58) and median frequency 2.5 seizures per month. Range being 1-8 per month. At the final followup at 6 months, only 2 persons experienced seizure and that too only single episodes. The difference in frequency is statistically significant (Wilcoxon Signed Ranks TestP <0.001). All the pre and post lacosamide cognition scores showed statistically significant positive correlation in this study. Conclusion: Excellent seizure control is observed in patients with refractory localization related epilepsy treated with lacosamide. Also, lacosamide has no serious adverse effects or drug interactions. In this study, it is observed that unlike many AEDs, lacosamide contributed to significant improvement in cognition and can improve the quality of life in such patients.

Introduction

Epilepsy is one of the most common disorders of the brain affecting around 50 million people worldwide.[1] Lacosamide (LCM), a third generation antiepileptic drug approved for adjunctive use in partialonset seizures has two novel mechanisms of action and favourable pharmacokinetic and safety profiles. $[2,3,4,5]$

More than $30 \%$ of epilepsy patients remain refractory to pharmacotherapy despite the advent of new AEDs over last two decades. [6] Because AEDs are the major therapeutic modality for epilepsy, the adverse effects of AEDs on cognition are important. [7] Previous studies on lacosamide $[2,8,9,10,11]$ observed that cognitive adverse effects (memory impairment, confusional state and disturbance in attention) were minimal and dose dependent.

The aim of this study was to obtain reliable data on cognitive effects of lacosamide in Indian patients with localization related epilepsy. 
medRxiv preprint doi: https://doi.org/10.1101/2021.05.13.21257196; this version posted May 23, 2021. The copyright holder for this preprint

(which was not certified by peer review) is the author/funder, who has granted medRxiv a license to display the preprint in perpetuity.

All rights reserved. No reuse allowed without permission.

\section{Objectives}

- To assess the adverse effects of lacosamide on cognition among patients with localization related epilepsy to whom lacosamide is given as adjuvant therapy.

- To study the seizure control profile of lacosamide in localization related epilepsy.

\section{METHODOLOGY}

This open labelled prospective observational study was done at Government Medical college, Thiruvananthapuram. Patients were recruited from epilepsy patients attending the Neurology OPD from January 2012 to December 2012. We recruited patients with drug refractory localisation related epilepsy who were given an adequate trial of at least two AEDs to maximum tolerated dose. Patients from both genders were included who had seizures of more than 6 months duration with a seizure frequency of at least 2 seizures in previous 3 months. We excluded patients who were pregnant, had renal or hepatic dysfunction, patients with pre-existent cognitive dysfunction, with psychosis, alcohol\& substance abuse. We also excluded patients with active suicidal plan/intent or active suicidal thoughts in the last 6 months and those with prior history of cardiac arrhythmia.

Sample size and selection: According to the prescription rate of lacosamide at the study setting, we expected a sample size of 30 . Only 25 patients were prescribed lacosamide during the study period. Of them, 22 satisfied the inclusion criteria and they were studied.

\section{STUDY TOOLS:}

- $\quad$ Pre tested Proforma

- Malayalam adaptation of Addenbrooke's cognitive examination (M-ACE)

- Digit backward memory span

- Block design

- $\quad$ Digit symbol Test

- $\quad$ Trail making test- part A

- $\quad$ Engel's Seizure Scoring System

- Naranjo's score

- Hospital Anxiety Depression Score

Ethics committee clearance was obtained, informed consent was obtained from each subject / guardian/ relative and confidentiality and anonymity of the patient's information were maintained

\section{Data collection}

This study comprehended minimum 8 visits-an initial visit, follow up visits every 2 weeks in the initial 2 months and monthly follow up visits for the next 4 months. Every subject was followed up at least for a period of 6 months after reaching the maintenance dose of lacosamide. 
medRxiv preprint doi: https://doi.org/10.1101/2021.05.13.21257196; this version posted May 23, 2021. The copyright holder for this preprint (which was not certified by peer review) is the author/funder, who has granted medRxiv a license to display the preprint in perpetuity. All rights reserved. No reuse allowed without permission.

At the first visit, socio demographic and clinical details were collected. Baseline evaluation of the seizure type and frequency was done. Baseline cognition was assessed. Engel system was used to score seizure burden at the first visit. Following these baseline assessments, lacosamide was prescribed.

At the second to seventh OPD visit, assessment of vital signs and weight followed by physical and neurologic examinations, seizure frequency, and adverse effects were done. Engels scoring and Naranjo's scoring were also done.

On the eighth OPD visit, apart from all other routine tests, battery of cognitive tests was repeated.

Collected data were entered in excel and analyzed using SPSS16. Relevant variables were expressed as means and standard deviation, medians, proportions and their $95 \% \mathrm{Cl}$, appropriately.

Appropriate statistical tests (Wilcoxon Signed Ranks Test, Mann-Whitney U, Kruskal-Wallis Test, One sample t test, Chi-square test, Fisher's exact, Spearman's correlation etc) were performed to find out the statistical significance of changes in the cognitive variables and association with other variables studied.

\section{RESULTS AND DISCUSSION}

Average age of the study population was 36.05 . Majority were males (63.6\%). $59.1 \%$ of the subjects were socially active. $31.8 \%$ had high school education and $27.3 \%$ had higher education. Most of the study subjects belonged to BPL category ( $81.8 \%)$. Family history of seizure disorder was reported by 2 ( $9 \%$ ) subjects.

\section{Baseline characteristics}

In the present study, the most common time of onset of epilepsy was adolescence $(31.8 \%)$ the next being childhood $(27.3 \%)$ and mean duration of epilepsy in the subjects was 20.8 years. Average baseline seizure frequency per six months was 21.4. Aura was present only in $23 \%$ of patients. $27.3 \%$ subjects had EEG abnormalities and $45.5 \%$ had CT/MRI abnormalities.

Most of the patients in this study were receiving 3 AEDs (59.1\%) concomitantly. In this study, 16 (72.7\%) subjects continued lacosamide till final follow up. Lacosamide was discontinued by $27.2 \%$ patients. Mean dose of lacosamide was $296.88 \mathrm{mg} / \mathrm{day}$. (Median dose $300 \mathrm{mg} /$ day)

\section{SEIZURE CONTROL PROFILE}

$87.5 \%$ of the study subjects had no seizures at 6 months of follow up. In the remaining $12.5 \%$ of patients, reduction in seizure frequency was observed. The difference in seizure frequency before and after lacosamide administration is statistically significant $(P<0.001)$. Engel's seizure score showed rapid decline following introduction of lacosamide. After $3^{\text {rd }}$ month it became low and remained steady, showing excellent seizure control.(Figure 1) The difference between initial and final Engel's score is statistically significant ( $p<$ 0.001). 
medRxiv preprint doi: https://doi.org/10.1101/2021.05.13.21257196; this version posted May 23, 2021. The copyright holder for this preprint

(which was not certified by peer review) is the author/funder, who has granted medRxiv a license to display the preprint in perpetuity.

All rights reserved. No reuse allowed without permission.

\section{BASELINE COGNITION}

In the baseline evaluation, majority of the patients showed cognitive impairment. Difference in mean M-ACE total score from population normal [88] was statistically significant. No significant association was observed between baseline M-ACE scores with most of the socio demographic and clinical variables studied.

Though not statistically significant, it was observed that as the age advances cognition decreases. Orientation showed a positive correlation with years of schooling $(p<0.05)$.

Of the 22 subjects, only $72.7 \%$ were able to perform Trail making test- part A. Mean baseline time taken to complete the test was $\mathbf{7 8 . 4}$ seconds. Difference in mean time taken by subjects from population average (29 seconds) was statistically significant ( $p<0.05$ ). Mean score of digit span backward was 2.1 , which was less than normal ( $4 \pm 1$ depending on age and intellectual abilities).

No significant association was observed between baseline TMT-A, digit backward, digit symbol and block design test scores with most of the socio demographic and clinical variables except TMT-A with education status (P 0.018) and Block design with Occupation. (P 0.021)

In this study, it was observed that, base line trail making test Part-A (TMT-A), digit backward and digit symbol tests are correlated with schooling $(p<0.05)$.

\section{PRE AND POST LACOSAMIDE COGNITION}

Difference in pre and post lacosamide M-ACE total scores was not significant (p 0.139).(Figure 2) Difference in Memory showed statistically significant improvement (P 0.007). Naming showed statistically significant improvement (P 0.037).

In this study, only $31.25 \%$ subjects showed a reduction in M-ACE total score from the baseline value.(Table1) Maximum number of people showed deterioration in sub-domain orientation $37.5 \%$ and minimum in memory and visuo-spatial abilities 18.75\% each.(Figure3)The association between number of AEDs and attention/concentration was statistically significant ( $\left.\begin{array}{l}p \\ 0.03\end{array}\right)$. Subjects from higher socio-economic status were having better improvement in total cognition scores (P 0.03) and sub-domain language (P 0.03) compared to subjects from low socio-economic background.

Though not significant, it was observed that as the age advances cognition decreases. Increase in number of AEDs and dose of lacosamide decreases cognition scores.

Negative correlation was shown by attention /concentration, memory, verbal fluency and total score with number of AEDs. Difference in pre and post lacosamide language score showed statistically significant positive correlation with years of schooling. Subjects getting four AEDs showed deterioration in post lacosa mide M-ACE total scores compared to those who got three or two AEDS. 
medRxiv preprint doi: https://doi.org/10.1101/2021.05.13.21257196; this version posted May 23, 2021. The copyright holder for this preprint

(which was not certified by peer review) is the author/funder, who has granted medRxiv a license to display the preprint in perpetuity.

All rights reserved. No reuse allowed without permission.

Though not statistically significant, it was observed that mean time taken to perform TMT-A (frontal/executive functions) was higher in post lacosamide subjects, which is an adverse cognitive response.

Post lacosamide digit backward test scores (which assess attention and working memory) showed significant improvement from baseline scores (P 0.04). Digit symbol (which measures psychomotor speed and sustained attention) and block design tests (which measures spatial perception, visual abstract processing, and problem solving) showed improvement, but not significant. In this study, $25 \%$ of subjects showed post lacosamide deterioration in TMT-A performance and only one subject showed deterioration in digit backward test.

Difference in TMT-A showed association with marital status (P 0.042) and educational status of the subjects (P 0.019). Digit backward test also showed association with occupation status of the subjects ( $P$ 0.047). It shows that subjects with higher education took lesser time for completing TMT-A in post lacosamide situation.

Significant association was observed between CT/MRI abnormalities Vs. TMT-A (P 0.016). EEG abnormalities showed significant association with Digit Symbol (P 0.03) and Block design (P 0.042) tests.

All the pre and post lacosamide cognition scores showed statistically significant positive correlation in this study. (Table 2, Table 3)

It was observed in this study that as age advances, time taken to complete TMT-A increases, which is an adverse cognitive effect. Though not significant, number of AEDs and dose of lacosamide were negatively associated with pre and post lacosamide difference in most of the cognition scores.

\section{DISCUSSION}

Several interacting factors including age of onset, seizure (type, duration, frequency, severity \& etiology), hereditary factors, psychosocial issues and cognitive side effects of antiepileptic drug (AED) therapy contribute to cognitive dysfunctions in epilepsy.[14] AEDs control seizures by causing global changes in the excitation levels in central nervous system. These alterations may result in cognitive deficits. Cognitive dysfunctions can negatively affect tolerability, compliance, and long-term retention of the treatment and can significantly affect every day functioning and quality of life of the patient. This study was aimed at assessing the effect of lacosamide on cognitive functions in patients with localization related epilepsy attending the neurology department of a tertiary care hospital.

In this study, lacosamide was discontinued by $27.2 \%$ patients; of whom $22.7 \%$ discontinued the drug themselves giving reasons such as dizziness (13.5\%) and financial burden (9\%). Nunes et al observed that discontinuation rate has been seen to be higher in lacosamide treated patients when compared to other AEDs.[15] Flores et al observed that $38 \%$ patients discontinued lacosamide, of which $20.8 \%$ withdrew due to intolerable ADRs alone. [16] 
medRxiv preprint doi: https://doi.org/10.1101/2021.05.13.21257196; this version posted May 23, 2021. The copyright holder for this preprint

(which was not certified by peer review) is the author/funder, who has granted medRxiv a license to display the preprint in perpetuity.

All rights reserved. No reuse allowed without permission.

$87.5 \%$ of the study subjects had no seizures at 6 months of follow up. In the remaining $12.5 \%$ of patients, reduction in seizure frequency was observed. In patients who had secondary GTCS, the seizure type changed to complex partial seizures. If a patient who used to experience GTCS earlier is experiencing only SPSs and CPSs later on, then it might be a sign of improved control of the seizures. In the present study, all patients reported improvement in seizure severity.

The difference in seizure frequency prior to lacosamide administration and post lacosamide is statistically significant $(P<0.001)$. This goes in accordance with various similar studies, where the median percentage reduction in seizure frequency per 28 days from baseline to the maintenance period for lacosamide ranged from $32.7 \%$ to $35.3 \%$ for $200 \mathrm{mg} /$ day and $36.4 \%$ to $41.1 \%$ for $400 \mathrm{mg} / \mathrm{day}$. [2,8,13]

Engel's seizure score showed rapid decline following introduction of lacosamide. After $3^{\text {rd }}$ month it became low and remained steady, showing excellent seizure control. The difference between initial and final Engel's score is statistically significant $(p<0.001)$.

Among the 22 patients observed in this study, 10 patients (45\%) complained of dizziness. In a similar study by Flores et al, $48.7 \%$ patients reported adverse effects. Sedation and dizziness were the most common ADRs followed by nausea.[16] The incidence of dizziness due to lacosamide in various studies range from $10.4 \%$ to $44.5 \%$.[17,18,13,2] It was observed that median dose of Lacosamide was equal (300mg/day) among both groups. Adverse events were not seen to be dose dependent in this study. But in many studies, adverse events were observed to be dose dependent. [19]

Though not significant, those who were concomitantly receiving sodium channel blocking AEDs in this study had higher frequency of dizziness compared to subjects receiving non sodium channel blocking AEDs. This is in accordance with the study by Novy et al, in which lacosamide when concomitantly administered with other sodium channel blocking AEDs was observed to cause increased side effects (diplopia, dizziness, drowsiness).[20]

In the present study, comparison of on-treatment versus baseline ECG results did not demonstrate any change in heart rate, PR interval, QT interval, or QRS duration in the study subjects. No cardiac adverse events were reported during the study period. Cardiac adverse effects including dose dependent PR interval prolongation, first and second degree AV block and atrial fibrillation/flutter has been observed with lacosamide in few studies. $[21,22,23]$ None of the subjects in the current study had any cardiac conduction problems or were taking drugs known to cause PR interval prolongation or had severe cardiac disease such as myocardial ischemia or heart failure at base line. This factor might be the reason for the lack of cardiac adverse events observed in the present study.

A total of 3 patients (13.5\%) withdrew from this study due to dizziness experienced during treatment with lacosamide. In various studies, percentages of withdrawals during the lacosamide treatment period because of adverse effects are $8 \%, 8.7 \%, 17 \%[2,13,24]$ etc. with dizziness, ataxia, nausea, vomiting, diplopia 
medRxiv preprint doi: https://doi.org/10.1101/2021.05.13.21257196; this version posted May 23, 2021. The copyright holder for this preprint

(which was not certified by peer review) is the author/funder, who has granted medRxiv a license to display the preprint in perpetuity.

All rights reserved. No reuse allowed without permission.

etc. being the most common reasons.[25] Causality of ADR assessed by Naranjo's Algorithm showed $100 \%$ probable reactions.

It was observed in this study that the mean difference in pre and post lacosamide scores deteriorated in orientation and attention/concentration. Verbal fluency remained same in pre and post lacosamide assessment. Language, visuospatial abilities and total score showed improvement. Difference in Memory showed statistically significant improvement (P 0.007). Recall and Retrograde memory showed statistically significant improvement. (Recall $P$ 0.02). Retrograde Memory (P 0.021)). Naming showed statistically significant improvement (P 0.037).

In a similar study, Helmstaedter observed that $9 \%$ of patients treated with lacosamide showed significant improvement in memory functions. (11)A meta analysis of 10 lacosamide randomized controlled trials for various indications observed that lacosamide is not associated with any significant cognitive adverse events. Memory impairment even though reported was found to be statistically not significant.[26]

The association between number of AEDs and attention/concentration was statistically significant ( $p$ 0.03). The observation in the present study is similar to the observation by Meador KJ that polytherapy (coadministration of multiple anticonvulsants) contributes to the risk of cognitive dysfunction and also increases the intensity of cognitive dysfunction. [27]

In this study, significant correlation was observed between pre and post lacosamide M-ACE total scores and all sub domain scores except Verbal fluency. (Table 2) Negative correlation was shown by attention /concentration, memory, verbal fluency and total score with number of AEDs. But years of schooling showed a positive correlation with M-ACE total score and most of its sub-domains. This goes in accordance with Meador KJ who observed that polytherapy (co-administration of multiple anticonvulsants) contributes to the risk of cognitive dysfunction and also increases the intensity of cognitive dysfunction. [27] This also goes in accordance with Mathuranath et al who observed that level of education is the demographic factor that significantly affects the M-ACE total score in Malayalam speaking population in southern INDIA. [28,29]

Post lacosamide digit backward test scores (which assess attention and working memory) showed significant improvement from baseline scores (P 0.04). In this study, 25\% of subjects showed post lacosamide deterioration in TMT-A performance and only one subject showed deterioration in digit backward test. This goes in accordance with Helmstaedter et al. who observed that $23 \%$ of patients treated with lacosamide showed significant improvement in executive functions and $14 \%$ patients deteriorated in executive functions.[11]

All the pre and post lacosamide cognition scores showed statistically significant positive correlation in this study. (Table 3) Of the subjects with EEG abnormalities, 50\% showed deterioration in psychomotor speed and sustained attention from baseline while none with normal EEG deteriorated. Statistically significant ( $p$ 0.05). 
medRxiv preprint doi: https://doi.org/10.1101/2021.05.13.21257196; this version posted May 23, 2021. The copyright holder for this preprint

(which was not certified by peer review) is the author/funder, who has granted medRxiv a license to display the preprint in perpetuity.

All rights reserved. No reuse allowed without permission.

Difference in TMT-A showed association with marital status (P 0.042) and educational status of the subjects (P 0.019). Digit backward test also showed association with occupation status of the subjects ( $P$ 0.047). It shows that subjects with higher education took lesser time for completing TMT-A in post lacosamide situation.

Significant association was observed between CT/MRI abnormalities Vs. TMT-A (P 0.016). EEG abnormalities showed significant association with Digit Symbol (P 0.03) and Block design (P 0.042) tests. This goes in accordance with Hermann et.al. who observed that baseline volumetric abnormalities are predictive of an increased risk of a progressively abnormal cognitive course. [30]

In this study, while looking at correlation, all tests except digit symbol showed a positive correlation. It was observed in this study that as age advances, time taken to complete TMT-A increases, which is an adverse cognitive effect. This goes in accordance with Tombaugh et al and Ashendorf et al who have observed that TMT- A performance declines with increasing age but not with education. [31,32]

Multiple factors might have played a role in the improvement in cognitive functions observed in this study. One factor can be the significant reduction in seizure frequency. It is a proved fact that continuing seizures contribute to cognitive deterioration in epileptic patients by inducing hippocampal sclerosis. [33] The reduction in seizure severity might also be an important contributor to the cognitive improvement. Previous studies have shown that severe seizures and status epilepticus reduces cognition. [34-36]

Another important factor might be the reduction in dose of or stopping of other concomitant AEDs which are associated with cognitive deterioration (phenobarbitone, carbamazepine etc.)

\section{Limitations}

This study was conducted as a prospective observational study. For better assessment of association an analytical study, preferably a randomized, controlled trial is desirable. Another important limitation was the small number of subjects included in this study. This was because lacosamide is a comparatively new drug and so it is being prescribed only to patients in whom treatment with first line AEDs fail. Another limitation was the restricted period of monitoring of adverse drug reactions. For complete assessment of adverse effects of lacosamide on cognition, patients have to be followed up over a longer time.

\section{Conclusion}

Excellent seizure control is observed in patients with refractory localization related epilepsy treated with lacosamide. Also, lacosamide has no serious adverse effects or drug interactions. In the above study, it is observed that unlike many AEDs, lacosamide contributed to significant improvement in cognition and can improve the quality of life in such patients.

\section{References}


medRxiv preprint doi: https://doi.org/10.1101/2021.05.13.21257196; this version posted May 23, 2021. The copyright holder for this preprint (which was not certified by peer review) is the author/funder, who has granted medRxiv a license to display the preprint in perpetuity. All rights reserved. No reuse allowed without permission.

1. Epilepsy [Internet]. [cited 2021 Mar 9]. Available from: https://www.who.int/news-room/factsheets/detail/epilepsy

2. Chung S, Ben-Menachem E, Sperling MR, Rosenfeld W, Fountain NB, Benbadis S, et al. Examining the clinical utility of lacosamide: pooled analyses of three phase II/III clinical trials. CNS Drugs. 2010 Dec;24(12):1041-54.

3. Vimpat ${ }^{\circledR}$ - Epilepsy | UCB [Internet]. [cited 2021 Mar 9]. Available from: https://www.ucb.com/ourproducts/Products/vimpat\%C2\%AE-epilepsy

4. Lacosamide: a review of preclinical properties - PubMed [Internet]. [cited 2021 Mar 9]. Available from: https://pubmed.ncbi.nlm.nih.gov/17461888/

5. Effects of the Novel Antiepileptic Drug Lacosamide on the Development of Amygdala Kindling in Rats Brandt - 2006 - Epilepsia - Wiley Online Library [Internet]. [cited 2021 Mar 9]. Available from: https://onlinelibrary.wiley.com/doi/full/10.1111/j.1528-1167.2006.00818.x

6. Granata T, Marchi N, Carlton E, Ghosh C, Gonzalez-Martinez J, Alexopoulos AV, et al. Management of the patient with medically refractory epilepsy. Expert Rev Neurother. 2009 Dec;9(12):1791-802.

7. Kim S-Y, Lee H-W, Jung D-K, Suh C-K, Park S-P. Cognitive Effects of Low-dose Topiramate Compared with Oxcarbazepine in Epilepsy Patients. J Clin Neurol. 2006 Jun;2(2):126-33.

8. Ben-Menachem E, Biton V, Jatuzis D, Abou-Khalil B, Doty P, Rudd GD. Efficacy and safety of oral lacosamide as adjunctive therapy in adults with partial-onset seizures. Epilepsia. $2007 \mathrm{Jul} ; 48(7): 1308-17$.

9. Lacosamide: efficacy and safety as oral adjunctive treatment for partial-onset seizures | Cochrane Library [Internet]. [cited 2021 Mar 9]. Available from: https://www.cochranelibrary.com/central/doi/10.1002/central/CN-00744961/related-content

10. Adjunctive lacosamide for partial-onset seizures: Efficacy and safety results from a randomized controlled trial - PubMed [Internet]. [cited 2021 Mar 9]. Available from:

https://pubmed.ncbi.nlm.nih.gov/19183227/

11. Helmstaedter C, Witt J-A. The longer-term cognitive effects of adjunctive antiepileptic treatment with lacosamide in comparison with lamotrigine and topiramate in a naturalistic outpatient setting. Epilepsy Behav. 2013 Feb;26(2):182-7.

12. Lacosamide: efficacy and safety as oral adjunctive treatment for partial-onset seizures | Cochrane Library [Internet]. [cited 2021 Mar 9]. Available from: https://www.cochranelibrary.com/central/doi/10.1002/central/CN-00744961/related-content

13. Halász $P$, Kälviäinen $R$, Mazurkiewicz-Beldzińska M, Rosenow F, Doty $P$, Hebert $D$, et al. Adjunctive lacosamide for partial-onset seizures: Efficacy and safety results from a randomized controlled trial. Epilepsia. 2009 Mar;50(3):443-53.

14. Epilepsy and Cognition - Bruce Hermann, Michael Seidenberg, 2007 [Internet]. [cited 2021 Mar 9 ]. Available from: https://journals.sagepub.com/doi/10.1111/j.1535-7511.2007.00151.x

15. Nunes VD, Sawyer L, Neilson J, Sarri G, Cross JH. Profile of lacosamide and its role in the long-term treatment of epilepsy: a perspective from the updated NICE guideline. Neuropsychiatr Dis Treat. 2013;9:467-76.

16. Flores L, Kemp S, Colbeck K, Moran N, Quirk J, Ramkolea P, et al. Clinical experience with oral lacosamide as adjunctive therapy in adult patients with uncontrolled epilepsy: a multicentre study in epilepsy clinics in the United Kingdom (UK). Seizure. 2012 Sep;21(7):512-7. 
medRxiv preprint doi: https://doi.org/10.1101/2021.05.13.21257196; this version posted May 23, 2021. The copyright holder for this preprint (which was not certified by peer review) is the author/funder, who has granted medRxiv a license to display the preprint in perpetuity. All rights reserved. No reuse allowed without permission.

17. Husain A, Chung S, Faught E, Isojarvi J, McShea C, Doty P. Long-term safety and efficacy in patients with uncontrolled partial-onset seizures treated with adjunctive lacosamide: results from a Phase III openlabel extension trial. Epilepsia. 2012 Mar;53(3):521-8.

18. Side Effects of Drugs Annual: A worldwide yearly survey of new data in adverse drug reactions. Elsevier; 2015. 693 p.

19. Development of lacosa mide for the treatment of partial-onset seizures - PubMed [Internet]. [cited 2021 Mar 9]. Available from: https://pubmed.ncbi.nlm.nih.gov/23859801/

20. Baulac M, Byrnes W, Williams P, Borghs S, Webster E, De Backer M, et al. Lacosamide and sodium channel-blocking antiepileptic drug cross-titration against levetiracetam background therapy. Acta Neurol Scand. 2017 Apr;135(4):434-41.

21. Rauck RL, Shaibani A, Biton V, Simpson J, Koch B. Lacosamide in painful diabetic peripheral neuropathy: a phase 2 double-blind placebo-controlled study. Clin J Pain. 2007 Feb;23(2):150-8.

22. Efficacy and safety of lacosamide in diabetic neuropathic pain: an 18-week double-blind placebocontrolled trial of fixed-dose regimens - PubMed [Internet]. [cited 2021 Mar 9]. Available from: https://pubmed.ncbi.nlm.nih.gov/19454870/

23. Degiorgio CM. Atrial flutter/atrial fibrillation associated with lacosamide for partial seizures. Epilepsy Behav. $2010 \mathrm{Jul} ; 18(3): 322-4$.

24. Chung SS, Kelly K, Schusse C. New and Emerging Treatments for Epilepsy: Review of Clinical Studies of Lacosamide, Eslicarbazepine Acetate, Ezogabine, Rufinamide, Perampanel, and Electrical Stimulation Therapy. J Epilepsy Res. 2011 Dec 30;1(2):35-46.

25. Doty P, Hebert D, Mathy F-X, Byrnes W, Zackheim J, Simontacchi K. Development of lacosamide for the treatment of partial-onset seizures. Ann N Y Acad Sci. 2013 Jul;1291:56-68.

26. Zaccara G, Perucca P, Loiacono G, Giovannelli F, Verrotti A. The adverse event profile of lacosamide: a systematic review and meta-analysis of randomized controlled trials. Epilepsia. 2013 Jan;54(1):66-74.

27. Meador KJ, Loring DW. Developmental effects of antiepileptic drugs and the need for improved regulations. Neurology. 2016 Jan 19;86(3):297-306.

28. Mathuranath PS, Cherian JP, Mathew R, George A, Alexander A, Sarma SP. Mini Mental State Examination and the Addenbrooke's Cognitive Examination: Effect of education and norms for a multicultural population. Neurology India. 2007 Apr 1;55(2):106.

29. Mathuranath PS, Hodges JR, Mathew R, Cherian PJ, George A, Bak TH. Adaptation of the ACE for a Malayalam speaking population in southern India. Int J Geriatr Psychiatry. 2004 Dec;19(12):1188-94.

30. Hermann B, Meador KJ, Gaillard WD, Cramer JA. Cognition across the lifespan: Antiepileptic drugs, epilepsy, or both? Epilepsy \& Behavior. 2010 Jan;17(1):1-5.

31. Tombaugh TN. Trail Making Test A and B: normative data stratified by age and education. Arch Clin Neuropsychol. 2004 Mar;19(2):203-14.

32. Trail Making Test errors in normal aging, mild cognitive impairment, and dementia - PubMed [Internet]. [cited 2021 Mar 10]. Available from: https://pubmed.ncbi.nlm.nih.gov/18178372/

33. Trimble MR. Cognitive Hazards of Seizure Disorders. Epilepsia. 1988;29(s1):S19-24.

34. Mula M, Trimble MR. Antiepileptic drug-induced cognitive adverse effects: potential mechanisms and contributing factors. CNS Drugs. 2009;23(2):121-37. 
medRxiv preprint doi: https://doi.org/10.1101/2021.05.13.21257196; this version posted May 23, 2021. The copyright holder for this preprint (which was not certified by peer review) is the author/funder, who has granted medRxiv a license to display the preprint in perpetuity. All rights reserved. No reuse allowed without permission.

35. Thompson PJ, Duncan JS. Cognitive decline in severe intractable epilepsy. Epilepsia. 2005 Nov;46(11):1780-7.

36. Dodrill CB. Progressive cognitive decline in adolescents and adults with epilepsy. Prog Brain Res. 2002;135:399-407. 
medRxiv preprint doi: https://doi.org/10.1101/2021.05.13.21257196; this version posted May 23, 2021. The copyright holder for this preprint (which was not certified by peer review) is the author/funder, who has granted medRxiv a license to display the preprint in perpetuity.

All rights reserved. No reuse allowed without permission.

Figure 1 Engel's Seizure score during the follow up period.

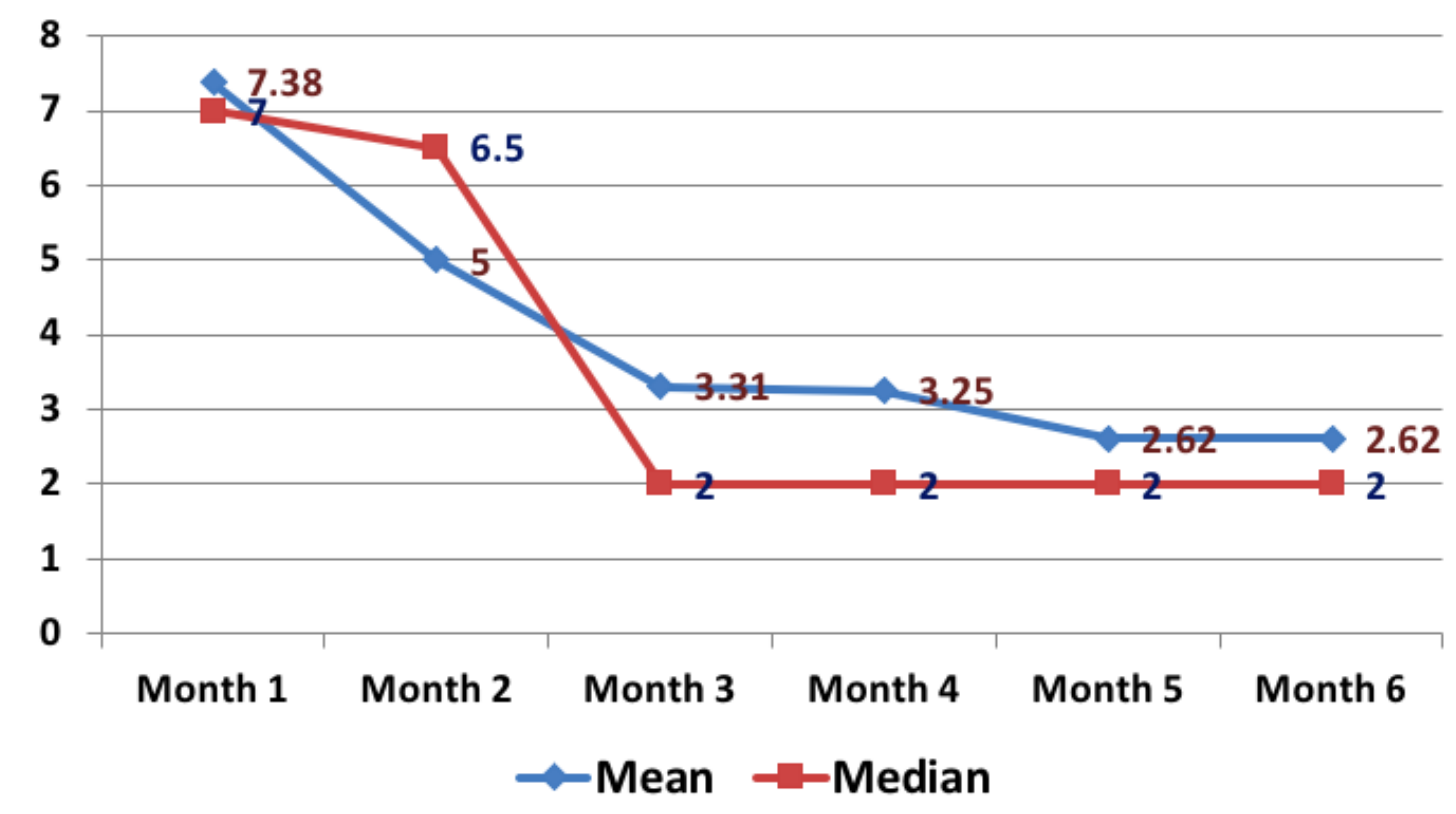

Figure 2 Clustered bar diagram comparing pre lacosamide and post lacosamide M-ACE scores 


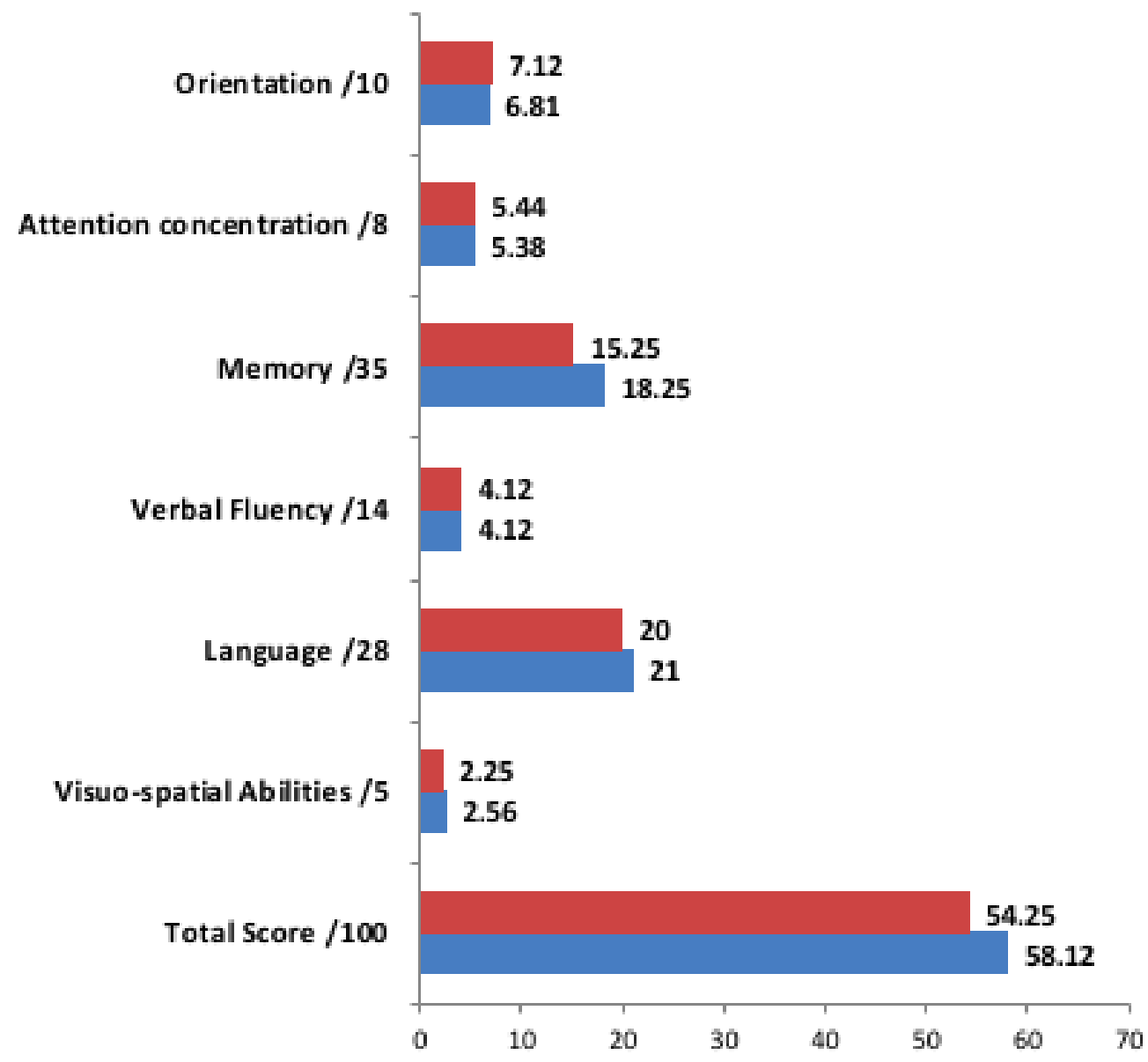

Pre Lacosamide Post Lacosamide

Table 1: Pre lacosamide and post lacosamide M-ACE scores and their significance.

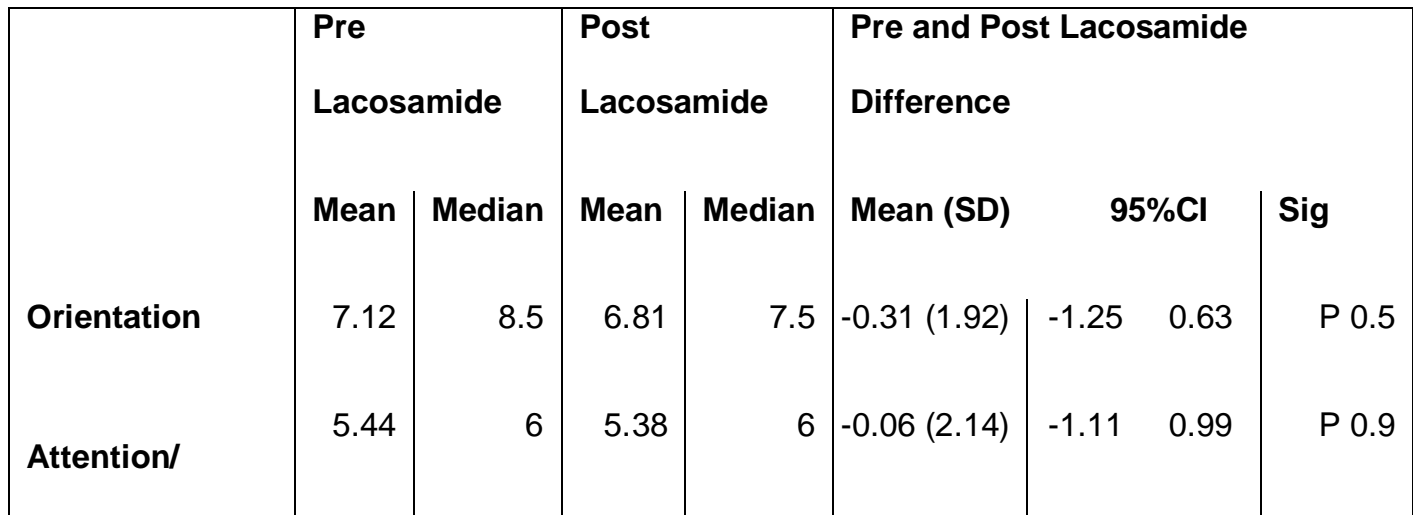




\begin{tabular}{|c|c|c|c|c|c|c|c|c|}
\hline \multicolumn{9}{|l|}{ Concentration } \\
\hline Memory & 15.25 & 15.5 & 18.25 & 19.5 & $3(3.86)$ & 1.11 & 4.89 & P 0.007 \\
\hline Verbal fluency & 4.12 & 4 & 4.12 & 4 & $0(3.16)$ & -1.55 & 1.55 & P 0.89 \\
\hline Language & 20 & 21 & 21 & 23.5 & $0.94(3.21)$ & -0.64 & 2.51 & P 0.053 \\
\hline \multicolumn{9}{|l|}{ Visuo-spatial } \\
\hline Abilities & 2.25 & 2 & 2.56 & 3.5 & $0.31(1.01)$ & -0.18 & 0.80 & P 0.19 \\
\hline Total Score & 54.3 & 60.5 & 58.1 & 63 & $3.88(10.7)$ & -1.37 & 9.12 & P 0.13 \\
\hline
\end{tabular}

*Wilcoxon Signed Ranks Test

Table 2: Correlation between differences in pre and post lacosamide cognition scores (M-ACE)

\begin{tabular}{|lll|}
\hline Pre Vs. Post lacosamide & Spearman's rho & P value \\
scores & & \\
Orientation & 0.774 & $<0.001$ \\
Attention Concentration & 0.506 & 0.045 \\
Memory & 0.603 & 0.013 \\
Verbal Fluency & 0.19 & 0.47 \\
Language & 0.85 & $<0.001$ \\
Visuospatial abilities & 0.88 & $<0.001$ \\
Total score & 0.78 & $<0.001$ \\
\hline
\end{tabular}


Table 3: Correlation of pre and post lacosamide cognition scores (Trail making test-part A, digit backward test, digit symbol test, block design test)

\begin{tabular}{|lll|}
\hline Pre Vs. Post lacosamide & Spearman's rho & P value \\
scores & & \\
Trail making test part-A & 0.666 & 0.025 \\
Digit backward & 0.822 & $<0.001$ \\
Digit symbol & 0.889 & $<0.001$ \\
Block design & & 0.051 \\
\hline
\end{tabular}

